\title{
Servikal spondilotik miyelopati; anterior cerrahi girişimler
}

\author{
Anterior approaches for cervical spondylotic myelopathy
}

\author{
Yetkin Söyüncü
}

Akdeniz Üniversitesi Tıp Fakültesi, Ortopedi ve Travmatoloji Anabilim Dalı, Antalya

\begin{abstract}
Servikal spondilotik miyelopati (SSM), spinal kordun bası altında kalması ve iskemisine bağlı ortaya çıkan klinik bir durumdur. SSM'nin cerrahi tedavi seçenekleri tartışmalıdır; bununla birlikte çoğu cerrah, şikayetleri uzun süredir devam eden hastalar ile klinik tablosunda bozulma olan hastalarda cerrahi tedavinin gerektiği konusunda aynı fikirdedir. Tedavideki amaç, spinal kord üzerindeki basıyı ortadan kaldırarak omurgayı anatomik ve stabil pozisyonda tespit etmektir. Spinal kord üzerine bası ön taraftan olduğu için tedavide anteriordan uygulanacak cerrahi tedavilerin tercih edileceği aşikardır. Spinal kanalın ön taraftan dekompresyonu ile birlikte stabilizasyon uygulamalarının, posteriordan yapılan yaklaşımlarla karşılaştırıldığında çok sayıda avantaj ve bazı dezavantajları vardır. Servikal kanaIın anteriordan dekompresyon işlemleri, tipik olarak anterior servikal diskektomi ve füzyon (ASDF) ile birlikte korpektomi girişimlerini içerir. Tek seviyeli SSM olgularında, ASDF işlemi altın standart olarak kabul edilir. Bu makalede anterior cerrahi girişimlerin farklı uygulamaları, komplikasyonları ve sonuçları tartışılmıştır.
\end{abstract}

Anahtar sözcükler: servikal miyelopati; servikal omurgaya anterior yaklaşım; anterior servikal diskektomi ve füzyon; anterior servikal korpektomi ve füzyon; komplikasyon
Cervical spondylotic myelopathy (CSM) is a clinical condition that manifests itself due to compression and ischemia of the spinal cord. The choice of surgical treatment for CSM remains controversial; however, most physicians agree that patients who experience symptoms for an extended period of time or progression of the disease require surgical intervention. The goal of the treatment is to decompress the spinal cord and stabilize the spine in neutral, anatomical position. Since the obstruction and compression of the cord are localized in front of the cord, it is obvious that an anterior surgical approach is the preferred one. Anterior decompression of the spinal canal plus fusion techniques for stabilization has several advantages and some disadvantages when compared to posterior options. Anterior cervical canal decompression approaches typically comprise corpectomy, and anterior cervical discectomy and fusion (ACDF). For single-level CSM, ACDF is accepted as the gold standard. In this article, different anterior surgical procedures, complications, and their outcomes are discussed.

Key words: cervical myelopathy; anterior approach, cervical spine; anterior cervical discectomy and fusion, anterior cervical corpectomy and fusion; complication ervikal spondilotik miyelopati (SSM)'de, omurgadaki dejeneratif değişikliklere bağlı spinal kordun fonksiyon bozukluğu söz konusudur. Miyelopatiye neden olabilecek esas olarak iki neden olabilir: spinal kordun direkt olarak basıya uğraması veya lokal kan akımında değişikliklere bağlı iskemik değişiklikler. Cerrahi tedavinin amacı, spinal stabiliteye zarar vermeden ve sagittal profile saygı göstererek maksimum dekompresyon elde edebilmektir. Bu uygulama, etkilenen bölgeye bağlı olarak; dekompresyon, füzyonlu ya da füzyonsuz basit diskektomiden, greftleme ve internal tespit uygulaması gereken vertebrektomiye kadar değişkenlik gösterir. Çalışmalarda, SSM'de patolojinin esas olarak anterior yerleşimli olduğu gösterildiğinden dolayı, omurgaya lezyonun olduğu bölge yani anteriordan yaklaşmak akıllıca görünmektedir. ${ }^{[1]}$

Anterior cerrahi yaklaşımlar; tek, iki ya da üç seviyeyi etkileyen hastalıkta dejeneratife servikal miyelopati (DSM)'yi tedavi etmek için en sık kullanılan cerrahi girişimlerdendir. Nöral yapılara dokunmaksızın, spinal kordun ön tarafının mükemmel şekilde ekspojuruna olanak verir. Anterior servikal yaklaşım ile, nöral foramen ve spinal kanalı genişletecek şekilde disk mesafesine distraksiyon yapabilmek mümkündür. Füzyon

- Illetişim adresi: Prof. Dr. Yetkin Söyüncü, Pınarbaşı Mah. Akdeniz Üniversitesi Tıp Fakültesi, Konyaaltı, Antalya Tel: 0242 - 2496000 e-posta: ysoyuncu@hotmail.com

- Geliș tarihi: 5 Nisan $2017 \quad$ Kabul tarihi: 5 Nisan 2017 
elde edebilmek için disk aralığına otogreft veya allogreft koymak gerekir. Füzyon, disk mesafesi kollabe olmadan yüksekliğini korumak, servikal lordozu devam ettirmek ve aynı zamanda etkilenen bölgeleri stabilize etmek ve yeni basıdan kurtarmak için önemlidir. ${ }^{[2,3]}$

Vertebra cismi önden spinal korda bası yapıyorsa, spinal kordu yeterli derecede dekomprese etmek ve takiben rekonstrüksiyonu ve stabilizasyonu için anteriordan servikal korpektomi gereklidir. Titanyum, polietereteketon (PEEK), allogreft veya otogreft gibi (iliak kanat, fibula) interbody cihazları rekonstrüksiyon ve füzyon amacıyla kullanılır. Hastanın gereksinimlerine ve kompresyon bölgesine göre kombine diskektomi ve korpektomiler yapılabilir. ${ }^{[2,4]}$

Uygulanacak cerrahi konusunda cerrahın seçimi primer olarak patoanatomiye, kısa ve uzun dönemde ortaya çıkabilecek komplikasyonlara, hastanın semptomlarına ve cerrahın deneyimine bağlıdır.

\section{SERVIKAL ANTERIOR CERRAHIYE NE ZAMAN KARAR VERELIM?}

\section{Servikal Omurganın Sagittal Dizilimi}

Fleksibl deformiteler, posterior dekompresyon ve stabilizasyon ile başarılı bir şekilde tedavi edilebilir; ancak, fikse servikal kifozda genellikle anterior dekompresyon ve stabilizasyon teknikleri tercih edilmelidir. Uchida ve arkadaşları, kifozu $\geq 10^{\circ}$ olan hastaları laminoplasti ile tedavi ettiklerinde, nörolojik iyileşmenin daha az olduğu rapor ettiler. ${ }^{[5]}$

Optimal lordoza sahip servikal sagittal dizilimin; ameliyat sonrası yaşam kalitesi üzerinde önemli etkisinin olduğu, miyelopati semptomlarının ciddiyetini ve dekompresyon sonrası fonksiyonel sonuçları etkilediği gösterilmiştir. ${ }^{[6]}$ Servikal kifozun, spinal kordda gerilme meydana getirerek miyelopati gelişiminde önemli bir rol aldığı düşünülmektedir. Smith ve arkadaşları ile Mohanty ve arkadaşları, ameliyat öncesi hastalarda mJOA (modified Japanese Orthopaedic Association scoring system) ile C2-C7 sagittal ve vertikal aksı arasında korelasyon olduğunu göstermişlerdir. ${ }^{[7,8]}$ Ameliyat öncesi kifoz varlı̆̆ının, hem anterior ve hem de posterior cerrahi uygulamalarda kötü cerrahi sonuçlar için bir risk faktörü olduğu gösterilmiştir. Her ne kadar halen ameliyat sonrası dizilimin sağlanmasının sonuçlar üzerinde olumlu etkisinin olduğu açık olmasa da, Shamji ve arkadaşlarının çalışmasına göre, kifoz ile birlikte olan DSM olgularında anterior cerrahi uygulamasını takiben cerrahi sonuçların daha iyi olduğunu söyleyebiliriz. ${ }^{[9]}$ Foraminal daralmaya neden olabileceğinden dolayı, posteriordan girişimle dizilimin aşırı düzeltilmeye çalışı Imasından kaçınmak gerekir. Diğer taraftan anterior girişim, disk mesafesini arttırarak foramenleri açar.

\section{Patoanatomi}

Iwasaki ve arkadaşlarının makalesi, her ne kadar ossifiye posterior longitudinal ligament (OPLL) hastaları konusunda olsa da, tepe şeklindeki lezyonların anteriordan dekompresyona daha iyi yanıt verdiğini, daha düz tipteki basıların ise laminoplasti ile iyileşebileceğini gösterdi. ${ }^{[10]} \mathrm{Bu}$ çalışmada, eğer kompresyon oranı $\% 60$ 'tan fazla ise hastaların nörolojik iyileşmesinin laminoplastiye göre anterior dekompresyon ile daha iyi olduğu gösterilmiştir. Bu çalışmadan elde edilen bulguları spondilotik miyelopati olgularına uyarlarsak; disk protrüzyonu ya da osteofitlerin spinal korda basısı sonucu oluşturduğu fasulye tipi anterior deformasyon, anterior cerrahi ile daha iyi tedavi edilebileceği söylenebilir. Kordun ön taraftan düzleştiği daha yaygın stenoz durumunda ise anterior ya da posterior dekompresyon yöntemleri uygulanabilir.

Arvin ve arkadaşları, manyetik rezonans (MR) görüntülerinde T2 sinyal artışı ve T1 sinyal düşüklüğünün, başlangıçtaki nörolojik durum ve cerrahi sonrası iyileşmeyi tahmin etmede yararlı olduğunu rapor ettiler. ${ }^{[11]}$ Karpova ve arkadaşları yaptıkları literatür taramasında, spondilotik miyelopati olgularında sinyal değişikliklerinin cerrahi tedavi sonuçları hakkında önceden fikir verici olabildiğini sonucuna vardılar. ${ }^{[12]} \mathrm{Her}$ ne kadar çalışmalarda sinyal değişikliklerinin cerrahi endikasyonlar ve ameliyat sonrası iyileşme için önemli olabileceği ifade edilse de, bu hasta grubunda anterior girişimlerin posterior girişimlerden daha iyi ya da kötü olduğuna dair bir veri yoktur.

\section{Etkilenen Seviye Sayısı}

Fraser'in yaptığı bir meta analizde, üç seviyeli patolojilerde anterior servikal diskektomi ve füzyon (ASDF) teknikleri uygulandığında, artrodez başarı oranlarının 1-2 seviye interbody yöntemleri ya da korpektomi yöntemlerinden daha düşük olduğu rapor edildi. Çok seviyeli korpektomi ile birlikte destek greft kullanılarak yapılan rekonstrüksiyon hasta ve hekim açısından daha zordur ve kombine artrodez işlemleri gerektirebilir. ${ }^{[13]}$

\section{Subluksasyon veya İnstabilite}

Dejeneratif değişiklikler subluksasyona neden olduysa ya da belirgin bir dinamik instabilite varsa, artrodez endikasyonu vardır. Miyelopatinin eşlik ettiği spondilotik hastalarda instabiliteyi tanımlayabilmek zor olabilir. Bu hastalarda, genellikle $2 \mathrm{~mm}$ translasyonal hareket kabul edilebilir; $4 \mathrm{~mm}$ ise cerrahi uygulama gerektirir. Bununla beraber; spinal kanal çapı, ağrı semptomları ve hastanın genel kondisyonu gibi diğer faktörler de önemlidir. 


\section{Kemik Kalitesi}

Uzun greftleri yerleştirmek ve anterior plak ile stabil tespitlerini sağlamada osteoporoz ciddi bir sorun oluşturabilir.

\section{Boyun Ağrısı}

Aksiyel boyun ağrısının nedeni tam olarak anlaşılamamış olsa da, dekompresyona ilave olarak füzyon, cerrahinin bir parçası olmalıdır. Liu ve arkadaşları yaptıkları bir meta-analiz çalışmasında, aksiyel boyun ağrısı açısından anterior veya posterior yaklaşımlar arasında bir fark bulamamışlardır. ${ }^{[14]}$

\section{CERRAHI TEKNIK}

ASDF cerrahisi gerçekleştirmek ve servikal omurganın anterior yüzeyine ulaşmak için Smith-Robinson yaklaşımı tercih edilmektedir. Platizmanın kesilmesini takiben boynun orta hat yapılarını mobilize etmek için, çok az kas hasarına neden olacak şekilde pretrakeal ve prevertebral fasyal planlar açılır. Diskektomiyi takiben, kıkırdak yapıdaki son plaklar ve posterior osteofitler temizlenir. Spinal kordun yeterli dekompresyonu için; posterior osteofitlerin çıkarılması, kısmi korpektomi, ya da posterior longitudinal ligament (PLL)'in çıkarılması gerekebilir; bununla birlikte, tüm bu girişimler spinal kord yaralanması riskini arttırabilir. Anterior servikal korpektomi ve füzyon (ASKF), çok seviyeli ASDF'ye bir alternatiftir ve benzer cerrahi yaklaşımla gerçekleştirilir. Bu teknikte, yüksek hızlı burr ve rongeur yardımı ile vertebra cisminin orta noktası yavaş yavaş çıkarılır.

Cerrahi yol, unkovertebral eklemler arasında ortalanacak şekilde ayarlanır; böylece spinal kordun tam olarak dekompresyonu elde edilebilir. Laterale doğru kemiklerin fazla alınmasından kaçınmak gerekir; aksi halde vertebral arter yaralanabilir. Arkada kalan ince kemik duvar ve PLL, mikro küret ve Kerrison Rongeur ile çıkarılır. Füzyon işlemi için farklı greft alternatifleri tercih edilebilir: otolog trikortikal iliak kanat grefti, allogreft, PEEK, metal kafesler veya korpektomi yapılmış kemikten elde edilen spongiyöz kemik ile birlikte kafes ya da strüktürel allogreftler. Çok seviyeli ASDF veya ASKF olgularında plak uygulaması iyi bir alternatiftir.

\section{ANTERIOR CERRAHI YAKLAŞIMIN AVANTAJLARI}

Anteriordan cerrahi yaklaşım seçenekleri hem tek ve hem de çok seviyeli SSM'de tercih edilir. Standart Smith-Robinson tekniğini kullanarak omurgaya ön taraftan yaklaşmak, deneyimli omurga cerrahları için oldukça kolaydır ve hedefe yöneliktir.

\section{Patolojiye Direkt Yaklaşım}

Olguların pek çoğunda miyelopati meydana getirecek şekilde kord üzerine bası yapan patolojiler; disk hernileri, osteofitik değişiklikler, kifoz ve subluksasyonlardır. Anterior yaklaşım; sadece basit bir diskektomi, hemikorpektomi, korpektomi ya da çok seviyeli korpektomi gibi daha geniş korpektomi teknikleriyle kord üzerindeki basının kaldırılmasına olanak verir. Unkovertebral eklemlerin tamamen çıkarılması ya da dekompresyonu, foraminotomi işlemleri, anteriordan başarılı bir şekilde yapılabilir.

Patolojinin direkt olarak ortadan kaldırılması ile birlikte, daha iyi bir nörolojik iyileşme beklenebilir. Pek çok bilimsel makalede nörolojik sonuçların, radikülopatinin eşlik ettiği ya da etmediği miyelopati olgularında en az posterior girişim kadar ve hatta çoğu olguda daha iyi olduğu rapor edilmiştir. ${ }^{[15,16]}$ Korpektomi ile laminoplastiyi karşılaştıran ve 10 yıllık sonuçları olan bir çalışmada, nörolojik sonuçların her iki grupta da benzer olduğu bildirilmiştir. ${ }^{[17]}$ Cunningham ve arkadaşları da anteriordan ve posteriordan yaklaşımlarda sonuçların benzer olduğunu ifade etmişlerdir. ${ }^{[18]}$ Bununla birlikte, Hirai ve arkadaşları anterior ve posterior yaklaşım deneyimlerini karşılaştırdıkları bir çalışmada, anterior yaklaşım ile özellikle üst ekstremite fonksiyonlarında olmak üzere daha iyi nörolojik iyileşme elde ettiklerini rapor ettiler. Posteriordan yaklaşım uygulanan hastalarda sonuçların daha kötü olması, ön taraftan bir miktar basının devam etmesine bağlanmıştır. ${ }^{[16,19]}$ Yakın zamanda yayımlanmış 10 makalenin meta-analizi sonucu, miyelopatinin cerrahi tedavisi için anterior ve posterior yaklaşımlar üzerinde odaklanılmış ve kanal çapı daralma oranı \%60 altında ise her iki grupta da nörolojik iyileşmenin eşit olduğu görülmüştür. ${ }^{[14]}$ Fehling ve arkadaşları anterior ve posterior yaklaşımları karşılaştırdıkları ileriye dönük çok merkezli SSM çalışmalarında, yararlı sonuçların her iki grupta benzer olduğunu rapor ettiler. Komplikasyon oranları da benzer olmakla birlikte, posterior cerrahilerde daha yüksek enfeksiyon görülme eğilimi rapor edilmiştir. ${ }^{[20]}$

\section{Deformitede Düzelme}

DSM'nin cerrahi tedavisini planlamada servikal dizilimin değerlendirilmesi oldukça önemlidir. Hasta sonuçlarını etkilediği için, servikal dizilimin korunması önemlidir. C2-C7 arasındaki normal servikal lordoz 20-35'dir ve bu değerler, hasta popülasyonu, hasta yaşı vb. faktörlere bağlıdır. ${ }^{[21]}$ Benzel ve arkadaşları, C3-C6 arasında herhangi bir omurga, C2 omurga cisminin postero-inferior kenarıdan mid-sagittal planda C7 omurga cisminin postero-inferior kenarına çizilen 
bir çizgiyi geçerse, servikal kifoz tanısı konulabileceğini ifade ettiler.[22]

Anterior diskektomiler ya da kemik grefti ve kafes rekonstrüksiyonu ile birlikte korpektomiler, servikal kifozun düzeltilmesine olanak verecektir. Uchida ve arkadaşları, ameliyat öncesi kifoz açısı $10^{\circ}$ 'den fazla olan spondilotik miyelopati olgularında, anteriordan korpektomi veya posteriordan laminoplasti uygulamalarının sonuçlarını karşılaştırdılar. Ortalama kifoz; anterior grupta \%46, laminoplasti grubunda $\% 15$ azald.. ${ }^{[5]}$ Interbody füzyon ile birlikte uygulanan diskektominin, destek greft ile birlikte uygulanan korpektomi yöntemlerine göre kifozu istatistiksel olarak daha iyi düzelttiği gösterildi. ${ }^{[23]}$ Fleksibl kifotik deformiteler, posteriordan yapilan dekompresyonu takiben enstrümantasyonlu füzyon ile birlikte istenilen pozisyonda tutulabilirken, rijid kifotik deformiteler, tipik olarak en azından anterior yaklaşım ve bazen kombine girişimler gerektirir.

\section{Artrodez}

Servikal omurgada uygulanacak füzyon işlemi, komşu segment dejenerasyonuna yol açtığından dolayı, iki ucu keskin bıçak gibidir. Hilibrand ve arkadaşları, geriye dönük olarak inceledikleri 374 hastada, daha önce servikal artrodez uygulanmış olgularda semptomatik komşu segment hastalığının insidansını her yıl için $\% 2,9$ olarak hesaplamışlardır. Onuncu yılda prevalans \%25 bulunmuştur. ${ }^{[24]}$ Nunley ve arkadaşları randomize bir çalışmada, anterior füzyon grubu ile artroplasti gruplarını içeren 170 hastada komşu segmentlerde radyolojik değişikliklere baktılar. Ortalama 42 aylık takipte komşu segmentlerde radyolojik değişiklikler; artrodez grubunda $\% 14,3$, artroplasti grubunda $\% 16,8$ oranında görülmüştür. ${ }^{[25]}$

Anterior artrodez teknikleri, posterior füzyon teknikleriyle karşılaştırıldığında, distraksiyon etkisi ile nöral foramenlerde indirekt olarak açılmaya yardımcı olabilir. Pek çok hastada, her iki yöntem de aksiyel boyun ağrısında rahatlamaya yardımcı olacaktır. Wada ve arkadaşları, miyelopati nedeniyle anterior korpektomi ve artrodez sonrası 10 . yılda hastaların \%15'inde boyun ağrısı rapor ederlerken, bu oran laminoplasti grubunda \%40 idi. ${ }^{[17]}$ Her ne kadar her iki grupta da posterior yaklaşım teknikleri kullanılmasına rağmen, Hightower ve arkadaşları, laminoplasti grubunda VAS (Visual Analog Scale) skorlarında belirgin iyileşme gözlemediklerini, ancak posterior laminektomi ve füzyon grubunda VAS skorlarının istatistiksel olarak daha iyi olduğunu ve artrodezin boyun ağrısını giderebileceğini söylemişlerdir. ${ }^{[26]}$

\section{ANTERIOR CERRAHI YÖNTEMLERIN SEÇIMI}

Anterior dekompresyon ve füzyon yöntemleri dört kategoride incelenebilir:

a) Diskektomi ve füzyon teknikleri.

b) Korpektomi ve yapısal greft teknikleri.

c) Hibrid yöntemler.

d) Servikal disk protezleri.

\section{Anterior Servikal Diskektomi ve Füzyon (ASDF)}

Diskektomi ve füzyon yöntemleri, kanalı dekomprese etmek amacıyla disk ve posterior osteofitin çıkarılmasını içerir (Şekil 1). Dekompresyonun posterior osteofitleri ve PLL'yi görecek şekilde uzatılması tartışmalıdır. Bohlman ve arkadaşları, posterior osteofit ve PLL çıkarmaksızın ASDF uyguladıkları 17 hastalık bir seri yayımladılar. Bir hasta hariç tamamında sonuçlar iyi veya mükemmeldi. ${ }^{[27]}$ Diğer yazarlar ise posterior osteofitlerin çıkarılmasının nörolojik iyileşmeyi hızlandırdığına inanırlar. Kadoya ve arkadaşları, 43 hastalık serisinde, mikroskop altında osteofitlerin emniyetli şekilde çıkarulabildiğini rapor etmişlerdir. ${ }^{[28]} \mathrm{Bu}$ teknik, vertebra gövdelerinin arkasından proksimal veya distale migre olmamış yumuşak disk hernileri için oldukça geçerli bir yöntemdir. Uç plaklardaki daha fazla spondilotik değişiklikler, kısmi korpektomi ile birlikte destek greft ya da kafes uygulamalarını gerektirebilir. Eğer kord basısının patoanatomisi ilgili seviyelerde diskektomi ve füzyon için uygunsa o zaman bu teknik, çok seviyeli korpektomi tekniklerine göre, çok seviyede distraksiyona olanak vermesi nedeniyle, servikal kifozun daha iyi düzeltilmesine olanak verir. ${ }^{[23]}$ Çok seviyeli ASDF sonrası nörolojik iyileşme oranları yüksek olmasına rağmen füzyon uygulanan seviye sayısı arttıkça non-union oranları artar. Otojen iliak kemik grefti kullanılarak tek seviye ASDF uygulanan olgularda kaynama oranı \%96 olarak verilmiştir. ${ }^{[29]}$ iki seviyeli ASDF olgularında bu oran \%75'e ve üç seviyeli ASDF olgularında ise \%56'ya düşer. ${ }^{\left[{ }^{[0]}\right.}$ Bazı yazarlar, bu riski azaltmak için recombinant human bone morphogenetic protein-2 (rhBMP-2) kullanmayı tercih ederler; ancak, bunun hava yolu obstrüksiyonuna neden olduğu rapor edildiği için dikkatli olunmalıdır. ${ }^{[31]}$ Anteriordan servikal plak uygulamalarıla birlikte, ASDF sonrası kaynama oranları artmıştır. Wang ve arkadaşları, iki seviyeli ASDF uyguladıkları 60 hastanın sonuçlarını yayımladılar. Bu çalışmada, 32 hastaya anteriordan plak uygulanırken, 28 hasta plak uygulaması yapılmadan tedavi edildi ${ }^{[30]}$; plak uygulaması yapılan hastaların tamamında ve plak uygulanmayan hastaların \%75'inde füzyon gözlendi. Wang ve arkadaşları tarafından yapılan bir başka çalışmada, üç seviye ASDF uygulanan hastalardan, plak uygulananlarda \%82, uygulanmayanlarda ise \%63 olarak rapor edildi. ${ }^{[30]}$ 

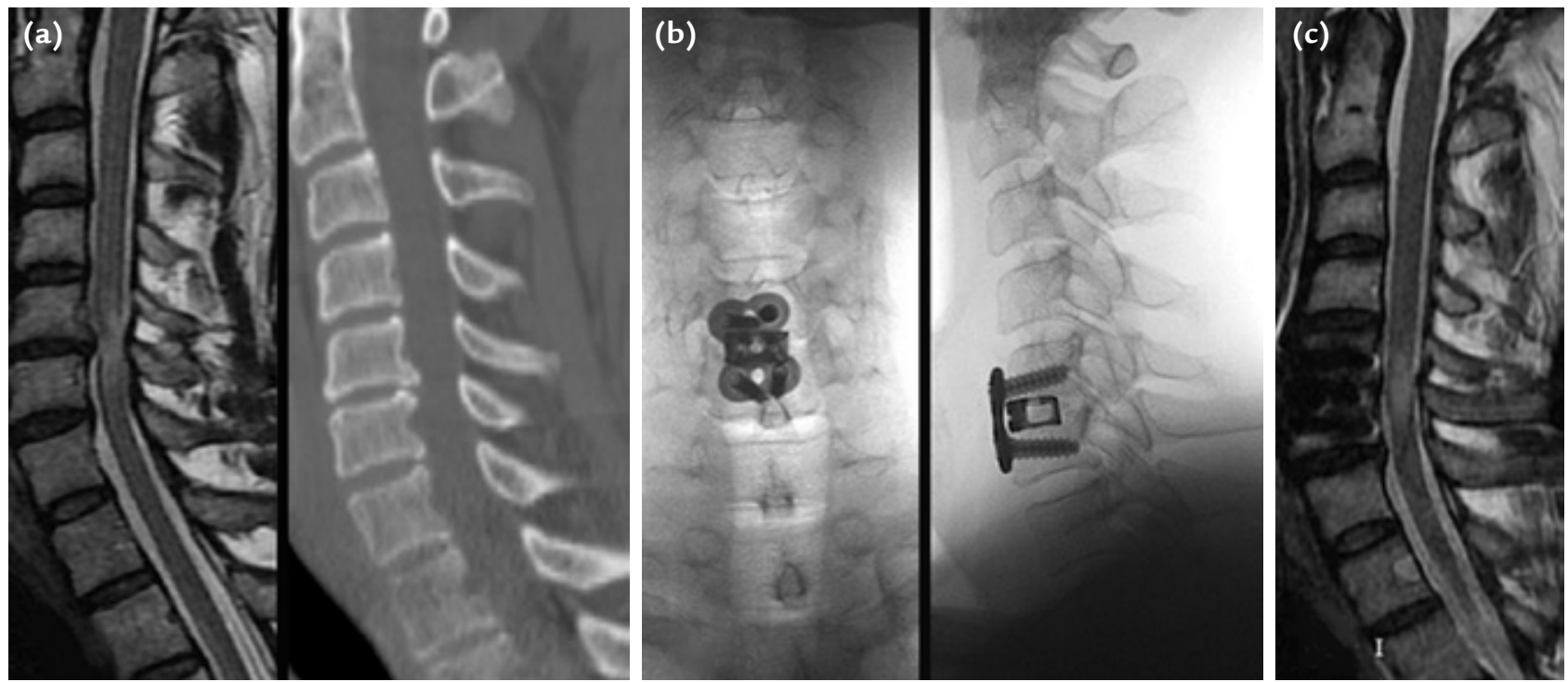

Şekil 1. a-c. Otuz iki yaşında erkek hasta; yürüme bozukluğu ve kollarda uyuşma şikayeti mevcut. Servikal dar kanal ve miyelomalazi saptanan hastanın ameliyat öncesi servikal MR ve BT sagittal kesitleri (a); ameliyat sonrası ön-arka ve yan grafileri (b); ameliyat sonrası sagittal MR kesiti (c). (DoçDr Mehmet Aydoğan'ın arşivinden alınmıştır.)

\section{Anterior Servikal Korpektomi ve Füzyon (ASKF)}

Anterior servikal korpektomi 1980'lerden itibaren sık kullanılmaya başlandı ve servikal omurgada miyelopati ve kord basısının tedavisinde ciddi bir ilerleme sağladı. Bilgisayarlı tomografi (BT) ve MR görüntülemede ilerlemeler ile birlikte, spinal kord basısına neden olan patolojiler daha iyi gösterilebilir hale geldi. Korpektomi ve destek grefti uygulamaları, omurga cismi arkasında spinal kord basısının olduğu durumlar için uygundur. Korpektomi, cerrahın tam olarak patoanatomiye ulaşmasına izin vererek emniyetli şekilde dekompresyona olanak verir. Bazen, çok seviyeli ve kord basısına neden olan uç plaklarda büyük osteofitlerin varlığında, her seviyede sınırlı diskektomi yerine çok seviyede yeterli dekompresyonu sağlamak ve nörolojik yaralanma riskini azaltmak için korpektomiler yapmak daha emniyetli olabilir. Anteriordan dekompresyon ve artrodez sonrası nörolojik iyileşme oranları \%80-90'dır. Anterior yaklaşım sadece direkt olarak santral kanalın dekompresyonuna yardımcı olmaz, aynı zamanda unkovertebral spur'ların çıkarılması ile radiküler semptomların da başarılı bir şekilde iyileşmesine olanak verebilir.

Önemli avantajlarından bir diğeri de, destek greft uygulaması ile omurganın artrodezidir. Bu yöntemle herhangi bir instabilite tedavi edilebilir ve geç dönemde ortaya çıkabilecek kifoz önlenebilir. Aynı zamanda, ameliyat öncesi kifozun düzeltilebilmesi de mümkündür. Küçük miktarlardaki rezidüel kifoz $\left(10^{\circ}\right.$ 'den az) klinik sorunlara yol açmaz. Bununla birlikte, daha ciddi sagittal deformite boyun ağrısına ve komşu segment instabilitesine neden olur. Çok seviyeli girişimlerde destek grefti uygulaması, kaynama için gerekli yüzey sayısını azaltır; bununla birlikte, çok seviyeli diskektomi ve interbody greftleme ile karşılaştırıldığında, non-union oranlarını düşürüp düşürmediği açık değildir. Hilibrand ve arkadaşları, sadece otogreft kullanılıp enstrümantasyon kullanmadıkları hastaları içeren geriye dönük bir çalışmada, yapısal destek grefti uygulananlarda kaynama oranını \%93 olarak verirken, çok sayıda interbody greft uygulamalarında bu oran \%66 civarındadır. ${ }^{[24]}$ Liu ve arkadaşları, anteriordan enstrümantasyon ve kafes uygulayarak, üç seviyeli ASDF ile hibrid yöntemleri ve iki seviyeli korpektomi yöntemlerini karşılaştırmışlardır. Kaynama oranları sırasıyla \%100, \%94,4 ve \%84,6 olup korpektomi grubu diğer iki gruba göre istatistiksel olarak daha düşük bulunmuştur. ${ }^{[32]}$ Bununla birlikte Lin ve arkadaşları, tümünde enstrümantasyon ve kafes kullanılan, üç seviyeli ASDF uygulanan 57 hastada ve iki seviyeli korpektomi yapılan 63 hastada \%100 kaynama rapor etmişlerdir. ${ }^{[23]}$ Servikal miyelopati tedavisinde anterior cerrahi girişimleri değerlendiren literatür taramasında, Samji ve arkadaşları, başarılı kaynama açısından her iki yöntemin birbirlerine üstünlüğü olmadığını, 
ancak klinik sonuç ve sagittal dizilim açısından çok seviyeli diskektomiyi korpektomiye tercih etmek gerektiğini raporlamışlardır. ${ }^{[33]}$

Artrodezle birlikte korpektomi uygulamasının bir diğer potansiyel avantajı, ameliyat sonrası ağrıda azalmadır. Artrodez hastaya yeni bir servikal omurga vermez, ancak yapılan çalışmalarda, dekompresyon sonrası artrodez uygulamalarının özellikle SSM'li olgularda ağrıda azalma sağladığı gösterilmiştir. Uzun segmental ya da ardışık OPLL olguları oldukça sert ve hatta otofüzyona uğramış olabilir ve dejeneratif spondilozlu pek çok hasta, ameliyat öncesi hissettikleri seviyelerde ağrı duymazlar.

Yöntemin bir dezavantajı, teknik olarak nispeten zor olmasıdır. Bu, özellikle OPLL hastaları ile çok seviyeli korpektomi uygulamalarında geçerlidir. Her ne kadar anormal disk ve kemik duradan uzaklaştırılsa da, bu sırada kord üzerine anormal bası uygulaması ve manipülasyondan kaçınmak gerekir. Bu durum, özellikle ciddi miyelopati olgularında geçerlidir (ribbon-like cord). Ciddi OPLL olgularında dura ossifiye olabilir ve cerrahi sonrası beyin omurilik sıvısı kaçağı görülebilir; bu durum oldukça sıkıntılı bir süreç ortaya çıkarabilir.

Anterior korpektomi ve destek greft uygulaması ile birlikte en sık karşılaşılan komplikasyonlar greft kaynaklı olanlardır. Greftin kayması ve kaynamaması halen önemli sorunlar olarak karşımıza çıkmaktadır. Greftler, tipik olarak alttaki vertebrada kırık oluşturarak ön tarafa doğru yer değiştirir ve bu durum genellikle revizyon cerrahisi gerektirir. Söz konusu komplikasyondan kaçınmada, vertebra cisminin kemik kalitesi oldukça önemlidir ve tedaviye karar vermede belirleyici olur. Daha önceden çok seviyeli laminektomi yapılmış hastalarda, anteriordan plak uygulaması yapılmasına rağmen greftin yerinden kayma riski oldukça yüksektir. Bu hastalar, en iyi çevresel olarak artrodez uygulaması ile tedavi edilirler.

Yöntemin diğer bir dezavantajı ise ameliyat sonrası hava yolunun monitorizasyonu, breys uygulaması gerektirmesi ve hareket kaybına neden olmasıdır. Enstrümantasyon yöntemlerinde ilerlemeler ile birlikte, breys kullanma ihtiyacı azalmıştır. Füzyon uygulamaları stabilite sağlar, ancak komşu segment dejenerasyon riski vardır. Bu durum, özellikle konjenital dar kanalı olan genç hastalarda daha büyük sorun oluşturur.

Bazı cerrahlar, ASKF uygulamalarını çok seviyeli ASDF uygulamalarıyla karşılaştırdıklarında, füzyon elde etmek için daha az greft yüzeyine ihtiyaç duyacaklarını belirtmişlerdir (örneğin; C4-C5 ve C5-C6 seviyelerinin dekompresyonunda, füzyon elde etmek için ASDF ile dört yüzey, ASKF ile iki yüzey gerekir). Nirala ve arkadaşları, enstrümantasyon kullanmadıkları ve çok seviyeli anterior füzyon uyguladıkları 201 hastayı incelemiş ve ASKF ile ASDF'den daha yüksek füzyon oranları elde edildiğini rapor etmişlerdir. ${ }^{[34]}$

Anteriordan plak uygulaması ile, üç seviyeli korpektomi (dört seviye disk aralığı) ve destek grefti uygulamalarında yeterli stabilitenin sağlanamadığı gösterilmiştir. Greft stabilitesini sağlamak, sagittal dizilimi devam ettirmek ve yeterli kaynama sağlamak için beraberinde posterior stabilizasyon da gerekir.

\section{Hibrid Anterior Rekonstrüksiyon}

Yakın zamanda, dekompresyon için korpektomi gereken durumlarda hibrid anterior rekonstrüksiyon yöntemleri gündeme gelmiştir. Ardışık üç seviyeyi ilgilendiren stenoz olgularında, üstteki iki disk mesafesi için tek seviye korpektomi yapılabilir. Daha sonra, en kaudaldaki disk mesafesine diskektomi yapılır. Arada oluşan boşluklar için iki adet kemik grefti yerleştirilip, takiben anteriordan servikal plak konulur. Inferiordaki vertebra cismi arkasında stenoz varsa bu teknik uygulanamaz. Hibrid ASDF ve korpektomi tekniği, dört seviye etkilenmesi olan hastalarda da kullanılabilir. Üstteki üç seviye disk mesafesini adresleyecek şekilde iki seviye korpektomi yapılırken, en alt seviyeye diskektomi uygulanır. Dört seviye stenozlu hastalar için alternatif yöntem, arada korpektomi yapılmamış bir seviye bırakarak üstte ve altta tek seviye olacak şekilde toplam iki adet korpektomi yapmaktır. Bu teknik, posteriordan stabilizasyon ihtiyacını ortadan kaldırabilir ve sıklıkla da uzun greft uygulamasından kaynaklanacak komplikasyonlardan kaçınmaya olanak tanır. ${ }^{[35,36]}$

Shen ve arkadaşları, rhBMP-2 ve allogreft kullanarak, hibrid teknikle çok seviyeli anterior füzyon uyguladıkları 127 hastada psödoartroz oranlarını araştırdılar. Genel oran \%10 iken, üç seviyeli olgularda \%4, dört seviyeli olgularda \%17 ve beş seviyeli olgularda $\% 22$ idi. Kaynamama olayı, tipik olarak en alt seviyede görüldü. ${ }^{[37]}$

Üç ve daha fazla seviyeyi içeren ve dekompresyon ile birlikte füzyon uygulanan hastalarda, anterior dekompresyonla birlikte çevresel füzyon önerilmiştir. ${ }^{[38]}$ Posteriordan segmental füzyon eklenmesinin kaynama oranını arttırdığı, greft ve plakla ilgili problemleri azalttığı bildirilmiştir. Bu teknik; üç ve daha fazla seviyeyi etkileyen spondiloz olgularında, fazla dekompresyon gerektiren OPLL olgularında, konjenital stenozun eşlik ettiği çok seviyeli spondilozis olgularında, dejeneratif kifoz ile birlikte çok seviyeli spondiloziste, postlaminektomi kifozunda, S şeklindeki eğriliklerde ve travma sonrası gelişen kifoz olgularında dikkate alınmalıdır. ${ }^{[39]}$ 


\section{Disk Artroplastisi}

Özellikle disk hernisine sekonder olmak üzere, tek ve hatta iki seviyeli DSM tedavisi için servikal artroplasti bir seçenektir. Cerrahi için en uygun koşullar; hastanın genç olması, faset eklem artritinin olmaması ve servikal hareketinin korunmasıdır. Füzyon işlemlerine üstünlüğü, hareketli sementi koruması ve komşu segment hastalığından kaçınılmasıdır. DSM'de disk hernisini tedavi etmek için, hem ASDF ve hem de artroplasti etkilidir. Buchowski ve arkadaşları, tek seviyeli disk kaynaklı miyelopati olgularında ASDF ve servikal disk uygulama sonuçlarını karşılaştırdılar. íki yıllık takipte nörolojik tabloda düzelme açısından, her iki grup arasında benzer sonuçlar buldular. ${ }^{[40]}$ Servikal artroplasti sırasında yetersiz dekompresyonun miyelopatik semptomların nüks etmesine yol açabileceğini unutmamak gerekir.

\section{ALTERNATIF ANTERIOR TEKNIKLER}

Tek ya da daha fazla seviye için, artrodez uygulamaksızın anteriordan dekompresyona olanak veren oblik korpektomi tekniği tanımlanmıştır. ${ }^{[11]} \mathrm{Bu}$ yöntemde, omurgaya anterolateralden yaklaşılır, vertebral arter ortaya konulur ve yaklaşım tarafındaki lateral patoloji ile anteriordan bası oluşturan patolojiyi temizlemek için oblik kanal açılır. Artrodez yapmaksızın stabiliteyi devam ettirmek için, ön taraf ile uzak lateralde yeterince kemik bırakılır. Kollabe disk ile birlikte doğal olarak stabil omurgaya sahip hastalar bu yaklaşım için idealdir. Zorlukları ve dezavantajları; yüksek oranda Horner sendromu görülmesi, vertebral arter yaralanması ve kifozu yeterince düzeltememesidir. Bazı yazarlar tatminkar sonuçlar yayımlamakla birlikte, bu teknik fazla popülarite kazanamamıştır.

Açık pencere korpektomi, 1999 yılında Özer ve arkadaşları tarafından tanımlanmış bir diğer tekniktir. Bu teknikte, vertebra cisminin arkası tamamen çıkarılırken anterior kısım bırakılır ve böylece, uzun destek greft kullanılmasına ihtiyaç kalmadan interbody kemik greftleri kullanılarak rekonstrüksiyon yapılır. Yazarlar, 15 hastalık geriye dönük serilerinde tatminkar sonuçlar bildirmelerine rağmen, bu yöntemin konvansiyonel korpektomi yöntemlerine olan üstünlüğü tartışmalıdır ve geniş bir kullanım görmemiştir. ${ }^{[42]}$

\section{ANTERIOR YAKLAŞIMIN DEZAVANTAJLARI}

Anterior servikal dekompresyon ve füzyon girişimleri sonrası ortaya çıkabilecek komplikasyonlar, yumuşak doku yapıları, kemik grefti ve nöral yapılarla ilişkili olabilir.

\section{Yüksek Komplikasyon Oranları}

Çok seviyeli anterior girişimler, posterior girişimlerle karşılaştırıldığında çok daha zordur ve daha fazla dikkat gerektirir. İki veya üç seviyeli anterior korpektomi girişimleri daha uzun sürer ve daha fazla kan kaybına yol açar. Hirai ve arkadaşları, laminoplasti grubuna göre anterior grupta komplikasyon oranlarının daha fazla olduğunu rapor ettiler ve bunlar, hava yolu ile ilgili sorunlar, yutma zorluğu ve psödoartrozdu. ${ }^{16]}$ Üç büyük derleme çalışmasında da aynı şekilde, çok seviyeli anterior girişimlerde posterior seçenekler ile karşılaştırıldığında, ameliyat sonrası komplikasyonların daha sık görüldüğü bildirilmiştir ${ }^{[14,18,43]}$ C5 kök paralizisi, laminoplasti uygulanan hastalarda \%4-16 arasında görülmekte olup, anterior korpektomi uygulanan hastalarda da benzer oranlarda görüldüğü rapor edilmiştir. ${ }^{[44]}$ Diğer risk faktörleri; ameliyat öncesi foraminal stenoz varlığı, OPLL ve asimetrik dekompresyondur. C5 palsi, profilaktik foraminotomi ile önlenebilir. ${ }^{[45]}$

Bununla birlikte, Fehlings ve arkadaşları çok merkezli ve ileriye dönük çalışmalarında, SSM hastalarında cerrahi sırasında komplikasyon riskinin, yaş, kombine anterior-posterior girişim, artmış kan kaybı ve ameliyat süresiyle ilişkili olduğunu, ancak sadece anterior ya da posterior girişimle ilgili olmadığını rapor ettiler. ${ }^{[46]}$

\section{Greft/Interbody Rekonstrüksiyonu}

Servikal omurganın anterior füzyonu için, sıklıkla anterior iliak krest ve fibuladan alınan yapısal otogreftler kullanılır. Taze otogreftlerin, bir miktar osteojenik potansiyeli yanında osteoindüktif ve osteokondüktif özellikleri de bulunur. Anterior iliak kanattan alınan yapısal kortikokansellöz greftler sıklıkla tercih edilir ve mekanik gücü posterior kreste göre daha yüksektir. Tek veya iki segmenti içeren interbody füzyon ile iki seviyeye kadar olan korpektomiler de tercih edilir. Korpektomi sonrası daha uzun defektlerin rekonstrüksiyonunda yapısal fibula grefti tercih edilmelidir. Dekompresyon sahasında grefti stabilize etmek için farklı yöntemler denenebilir. Çok sayıda vertebrektomi olgularında vaskülarize fibula uygulaması füzyon olayını hızlandırabilir. ${ }^{[47]}$

Her ne kadar son yıllarda otojen iliak kanat grefti altın standart olarak kabul edilse de, anteriordan plaklama teknikleri ile daha yüksek füzyon oranları elde edilmesi ile birlikte allogreft kullanımı daha yaygınlaşmıştır. Samartzis ve arkadaşları, iki veya üç seviyeli ASDF olgularında enstrümantasyon kullanımı ile birlikte otogreft ve allogreft uygulamalarının sonuçlarını geriye dönük olarak değerlendirmişler; füzyon oranlarında istatistiksel olarak bir fark bulamazlarken, radyolojik 
iyileşme oranlarını allogreftlerde $\% 94,3$ ve otogreftlerde $\% 100$ olarak vermişlerdir. ${ }^{[4]}$ Bu çalışmada etkilenen seviye sayısı sonuçlar üzerine etki etmemesine rağmen, diğer yazarlar üç seviyeli ASDF girişimlerinin halen sorunlu olduğunu göstermişlerdir. ${ }^{[13,49]} \mathrm{Bu}$ yazarlar, ağır sigara kullanıcıları ile anteriordan psödoartroz onarımında otojen kemik grefti kullanılmasını önerirler.

PEEK veya titanyum örgü kafesler gibi kemik grefti yerine kullanılan materyaller ile de oldukça iyi sonuçlar yayımlanmıştır. Ba ve arkadaşları PEEK kafes (cage), anterior plak ve lokal otogreft uyguladıkları 207 ASDF olgusunda \%100 oranında kaynama elde etmişlerdir. ${ }^{\left[{ }^{00}\right]}$ Petr ve arkadaşları da, PEEK, plak uygulama ve otogreft ile $\% 100$ kaynama oranları vermişlerdir. Kafes içine kemik grefti konulması önemlidir. Pechlivanis ve arkadaşları, sadece PEEK kafes plak uygulaması yaptıkları hastalarda non-union oranını \%28 olarak vermişlerdir. ${ }^{[51]}$ PEEK kafeslerin ameliyattan bir yıl sonra önemli miktarda (\%25) çöktüğü gösterilmiştir. Sadece titanyum interbody kafes kullanılan ve plak tespiti yapılmayan tek ya da iki seviyeli ASDF olgularında, Niu ve arkadaşları, füzyon oranını \%86,5 olarak bildirmişler, ancak $\% 16,3$ oranında 3 mm'den fazla çökme görülmüştür. ${ }^{[52]}$ Uribe ve arkadaşları, titanyum örgü kafes ve anteriordan plak uyguladıkları çok seviyeli olgularda \%97,6 kaynama oranı ve mükemmel klinik sonuçlar yayımlamışlardır. ${ }^{[53]}$ Greft alınan bölgede ortaya çıkan ağrı $\% 2,4$ oranında görülür. Interbody kafeslerin kullanılması ile birlikte, donör saha ile ilgili ağrı sorunu daha az görülmektedir. Kafesler, disk mesafesini doldurarak stabilite sağlarken daha az kemik greftine ihtiyaç duyulmasına neden olmaktadır. Bununla beraber ,füzyon oranlarına bakıldığında, iliak kanattan kemik grefti uygulamasının sonuçlarının kafes uygulamasına göre daha iyi olduğu gösterilmiştir.

Anteriordan strut greft ile rekonstrüksiyon girişimlerinde stabiliteyi ve iyileşme potansiyelini arttırmak için, uygulanacak cerrahi tekniğe özen göstermek gerekir. Pek çok cerrah, üç veya daha fazla korpektomi uygulanan hastalar ile ciddi kifoz veya osteoporozu olan hastalarda, iki seviye korpektomi sonrası greft stabilitesini sağlamak için anterior ve posteriordan stabilizasyon uygulamayı tercih ederler. ${ }^{[54]}$ Anteriordan çok seviyeli diskektomi ve füzyon sonrası plak uygulaması yapılsa bile kaynamama riski oldukça yüksektir. ${ }^{[49]}$

\section{Yutma Zorluğu ve Hava Yolu Sorunları}

Ameliyat sonrası ortaya çıkan yutma güçlüğü hastaların \%2-48'inde görülür. ${ }^{[13]}$ Semptomlar genellikle geçici olmasına rağmen, hastaların \%12'sinde kronik yutma güçlüğü rapor edilmiştir. Pek çok nedeni olmakla birlikte, uzun süreli ekartasyon ve faringeal pleksusun yaralanmasına bağlı özefagusun üst kısmının denervasyonu sonucu genellikle hematom gelişir. Yutma güçlügüü için risk faktörleri; 60 yaşından büyük olmak, çok seviyeli yapılan cerrahi girişimler, bayan hastalar, revizyon cerrahileri, kalın plak kullanılması ve ameliyat öncesi uzun süre ağrı olması olarak sıralanabilir.

Hava yoluna ilişkin komplikasyonlar herhangi bir zamanda görülebilmesine rağmen, anteriordan uzun korpektomi ve rekonstrüksiyon uygulanan olgular ile kemik morfojenik protein kullanılan olgularda daha fazla problemlidir. Anterior girişim sonrası ortaya çıkan disfajinin, son dönemlerde sanılandan fazla olduğu belgelenmiştir. Yutma zorluğu şikayetlerinin önemli kısmı kısa sürede ve hızla geriler, ancak bu sorun küçük oranda hasta grubunda yıllarca devam edebilir.

Daha yeni ve düşük profilli plaklar ve ameliyat sırasında steroid kullanımının retrofaringeal ödemi azaltarak disfajiyi azaltmada etkili olduğu gösterilmiştir. ${ }^{[55]}$

Anterior servikal cerrahinin postansiyel olarak öldürücü bir komplikasyonu, ödem ve hematomdan kaynaklanan hava yolu obstrüksiyonudur. Emery ve arkadaşları, ciddi miyelopatisi olan hastaların tamamının ameliyattan sonra entübe şekilde izlenmesini önermişlerdir. ${ }^{[56]}$ Anterior servikal girişim uygulanmış çok sayıda hastayı içeren yakın zamandaki bir araştırmada, cerrahi süre ile dekompresyon yapılan seviye sayısının, hastaların ameliyattan sonra entübe kalıp kalmayacakları konusunda en önemli kriterler olduğu bildirilmiştir. ${ }^{[57]}$ Yazarlar, total servikal ekartasyon süresinin 2,5 saatten ya da toplam ameliyat süresinin 3 saatten daha az olduğu olgularda hastaların ekstübe edilmesini önermişlerdir. Entübasyonu zor olan hastalar için, ameliyat süresi 1,5 saatten az ise ekstübasyon önermişlerdir. Bu parametreleri kullanmak şartıyla, yazarlar, ödeme bağlı solunum zorluğu yaşayan hasta ile karşılaşmamışlardır. Hematom oluşumuna bağlı 256 hastanın dördünde ameliyattan $30-48$ saat sonra solunum sıkıntısı geliştiği rapor edilmiştir. Bu dört hastanın hepsi de tekrar entübe edilerek hematomlar boşaltılmıştır.

\section{Hareket Kısıtlılı̆ı ve Ameliyat Sonrası Breys}

Çoğu diskektomi ve füzyon uygulanmış hasta ile çok seviyeli korpektomi yapılmış tüm hastalarda, erken dönemde stabiliteyi sağlamak ve başarılı bir artrodez elde etmek için cerrahi sonrası dönemde breys kullanılmalıdır. Anterior girişimleri takiben breys kullanma gerekliliği, breys tipi ve kullanma süresi hakkında kanıta dayalı kılavuzlar oluşturacak şekilde yüksek kaliteli çalışmalar bulunmamaktadır. 


\section{Komşu Segment Hastalığı}

Anterior servikal interbody füzyon sonrası komşu segment hastalığı görülme olasılığı nispeten sıktır. Sıklığı \%11-33 arasında yayımlanmıştır. ${ }^{[58]}$ Komşu segment disk dejenerasyonu semptomatik hal alırsa, bazen cerrahi gerektirebilir. Uzun dönem takip çalışmalarında, revizyon cerrahisi uygulama oranları \%6,3-16,9 arasında rapor edilmiştir. ${ }^{[24]}$ Hilibrand ve arkadaşları, 409 adet anterior servikal füzyon işlemi yapılmış 374 hastanın retrospektif olarak uzun dönem raporlarını yayımlamışlardır. Komşu segment dejenerasyon insidansının her yıl \%3 olduğunu bulmuşlardır. Dejenerasyon sıklıkla C5-C6 ve C6-C7 seviyelerinde görülmekte, çok seviyeli füzyon uygulamasına göre tek seviye füzyon uygulamalarında daha sık izlenmektedir.

\section{Potansiyel Komplikasyonlar}

Potansiyel riskler; spinal kord yaralanması, vasküler yaralanmalar, trakea ve özefagus yaralanmaları ve enstrümantasyon yetmezlikleridir. Özefagus yaralanması, direkt yaralanma ya da kuvvetli ekartasyon sonucu oluşabilir; kötü pozisyonda konulmuş plak veya vidaya bağlı olarak geç dönemde de ortaya çıkabilir. Zamanında ve uygun şekilde tedavi edilmezse ölümcül enfeksiyonlarla sonuçlanır. Fehling ve arkadaşla$\mathrm{rl}$, spondilotik miyelopati nedeniyle sadece anterior, posterior ya da kombine girişimlerde bulundukları 302 hastayı analiz ettiler ve cerrahi sırasında komplikasyon oranlarını \%15,6 olarak rapor ettiler. ${ }^{[46]}$ En sık karşılaşılan komplikasyonlar, kardiyopulmoner nedenler (\%3), disfaji (\%3) ve yüzeyel yara enfeksiyonudur $(\% 2,3)$. Olguların \%1,3'ünde cerrahi sırasında miyelopatinin daha kötüye gittiği rapor edilmiştir. Ameliyat sonrası ikinci yıl takipte geç komplikasyon oranı \%4,4 olarak bildirilmiştir. Ameliyat sırasında hastanın yaşının yüksek olması, ameliyat süresinin uzamış olması, kombine anterior ve posterior girişim uygulanması, komplikasyon riskini arttırır. Zhu ve arkadaşları, sekiz çalışmadan oluşan bir meta-analiz çalışmasında, posterior cerrahiyle karşılaştırıldığında anterior cerrahinin komplikasyon oranının daha yüksek olduğu hesaplamışlardır (\%8,57'ye karşı \%0,3). Bununla beraber, anterior yaklaşımda nörolojik iyileşmenin daha iyi olduğu görülmüştür. ${ }^{[43]}$

\section{ÇOK SEVIYELI SSM OLGULARINDA ANTERIOR VE POSTERIOR YAKLAŞIMLARIN KARŞILAŞTIRILMASI}

DSM'de, hem anterior ve hem de posterior yaklaşımlar hastaların nörolojik durumlarında düzelme sağlar. Bazı sistematik derleme yazılarında, anterior yaklaşımlarla ameliyat sonrası daha iyi nörolojik iyileşme olduğuna dair raporlar vardır. Bununla birlikte, iyileşme oranları hem meta analiz ve hem de sistematik derleme çalışmalarında benzer olarak bulunmuştur. ${ }^{[43]}$ Servikal bölgede anteriordan yapılan çok seviyeli dekompresyon ve füzyon girişimlerinde, posterior cerrahi ile karşılaştırıldığında komplikasyon oranları daha fazla bulunmuştur.

Fehling ve arkadaşları, çok merkezli ve ileriye dönük olarak 264 DSM hastasının anterior ve posterior cerrahilerinin sonuçlarını karşılaştırmışlardır. Yüz altmış dokuz hasta anterior cerrahi ve 95 hasta posterior cerrahi ile tedavi edilmiş olup $\% 87$ oranında takipleri yapılmıştır. Her ne kadar anterior cerrahi uygulanan hastalar daha genç ve miyelopatileri daha az ciddi olsa $\mathrm{da}$, anterior ve posterior cerrahinin benzer etkinliğe sahip oldukları sonucuna varılmıştır. ${ }^{[21]}$

Yonenobu ve arkadaşları, çok seviyeli SSM olgularında laminektomi ile korpektomi ve ASDF sonuçlarını karşılaştırdılar. ${ }^{[59]}$ Takip ettikleri 95 hastadan çok seviyeli korpektomi yapılan hastalarda, laminektomi grubu ile karşılaştıııldığında iyileşme oranının ciddi derecede daha yüksek ve geç nörolojik bozulmanın daha düşük olduğu rapor ettiler. Çok seviyeli korpektomi ASDF ile karşılaştırıldığında ise, nörolojik iyileşmenin daha iyi olduğu görülmüştür. Yunenobu ve arkadaşlarının 1992 yılındaki yayınında, laminoplasti ile subtotal korpektomi sonuçları karşılaştırılmıştır. ${ }^{[60]} \mathrm{mJOA}$ maksimum iyileşme oranları ile final iyileşme oranları açısından iki teknik arasında bir fark bulunmamıştır. Komplikasyon oranları açısından ise dikkati çekecek oranda farklılık rapor edilmiştir (\%29 korpektomi, \%7 laminoplasti). Yazarlar, çok seviyeli servikal miyelopatide laminoplastinin öncelikli tedavi seçeneği olarak düşünülmesi gerektiği sonucuna varmışlardır.

Edward ve arkadaşları, üç ve daha fazla seviyeli stenoza bağlı miyelopati ve lordotik sagittal dizilimi olan hastalarda korpektomi ve laminoplasti sonuçlarını karşılaştırdılar. Subjektif ve objektif nörolojik iyileşmenin her iki grupta da benzer olduğu, ancak komplikasyon oranlarının korpektomi grubunda daha fazla olduğunu rapor ettiler. ${ }^{[61]}$

Wada ve arkadaşları, çok seviyeli SSM nedeniyle korpektomi ve laminoplasti yapılan hastaların en az 10 yıllık sonuçlarını yayımladılar. Son takiplerde, her iki yöntemin de benzer nörolojik iyileşme sağladığı gözlendi. Korpektomi yapılan olgularda rapor edilen en önemli sorunlar, psödoartroz (\%26) ve semptomatik olmayan komşu segment hastalığı idi. Laminoplasti grubunda ise hareket kısıtlılığ ve aksiyel boyun ağrısı (\%40) sık karşılaşılan sorunlardı. ${ }^{[17]}$

İki seviyeli diskektomi sonuçları, tek seviye korpektomiye benzer. Bununla beraber, ASKF diskektomi ile 
karşılaştırıldığında daha uzun ameliyat süresi ve daha fazla kanama ile karşılaşıımıştır. ${ }^{[62]}$ Ayrıca, diskektomiler korpektomi ile karşılaştırıldığında, cerrahi sonrası servikal lordoz ve disk mesafesinde daha iyi düzelmeler olduğu görülmüştür. Her ne kadar korpektomiler çok seviyeli diskektomilerden daha düşük oranda psödoartroza neden olsa da, kemik greft temas alanının daha düşük olması nedeniyle vidalarda daha fazla stres oluşacaktır. Seçilecek cerrahi, cerrahın deneyimi ve hastanın radyolojik bulgularına bağlıdır.

\section{SONUÇ}

Servikal miyelopatinin cerrahi tedavisi, her hastanın klinik ve radyolojik bulgularına göre belirlenmelidir. Tek seviyeli stenoza bağlı miyelopati olguları ASDF ile başarılı şekilde tedavi edilebilir. Tek başına korpektomi veya ASDF ile kombinasyonu, iki veya üç seviyeli olgularda spinal kanal dekompresyonu için uygundur. Hastanın sagittal dizilimine bağlı olarak, üç ve daha fazla seviyeyi etkileyen stenoz olgularında, anterior dekompresyon ile birlikte çevresel füzyon veya laminoplasti tercih edilir.

\section{KAYNAKLAR}

1. Kang JD, Bohlman HH. Cervical spondylotic myelopathy. Curr Opin Orthop 1996;71:13-21.

2. Chibbaro S, Benvenuti L, Carnesecchi S, Marsella M, Pulerà F, Serino D, Gagliardi R. Anterior cervical corpectomy for cervical spondylotic myelopathy: experience and surgical results in a series of 70 consecutive patients. J Clin Neurosci 2006;13(2):233-8. Crossref

3. Emery SE. Anterior approaches for cervical spondylotic myelopathy: which? When? How? Eur Spine J 2015;24 Suppl 2:150-9. Crossref

4. Macdonald RL, Fehlings MG, Tator $\mathrm{CH}$, Lozano A, Fleming JR, Genitili F, Berstein M, Wallace MC, Tasker RR. Multilevel anterior cervical corpectomy and fibular allograft fusion for cervical myelopathy. J Neurosurg 1997;86(6):990-7. Crossref

5. Uchida K, Nakajima H, Sato R, Yayama T, Mwaka ES, Kobayashi S, Baba H. Cervical spondylotic myelopathy associated with kyphosis or sagittal sigmoid alignment: outcome after anterior or posterior decompression. J Neurosurg Spine 2009;11(5):521-8. Crossref

6. Shamji MF, Ames CP, Smith JS, Rhee JM, Chapman JR, Fehlings MG. Myelopathy and spinal deformity: relevance of spinal alignment in planning surgical intervention for degenerative cervical myelopathy. Spine (Phila Pa 1976) 2013;38(22 Suppl 1):S147-8. Crossref

7. Mohanty C, Massicotte EM, Fehlings MG, Shamji MF. Association of preoperative cervical spine alignment with spinal cord magnetic resonance imaging hyperintensity and myelopathy severity: analysis of a series of 124 cases. Spine (Phila Pa 1976) 2015;40(1):11-6. Crossref

8. Smith JS, Lafage V, Ryan DJ Shaffrey CI, Schwab FJ, Patel AA, Brodke DS, Arnold PM, Riew KD, Traynelis VC, Radcliff K, Vaccaro AR, Fehlings MG, Ames CP. Association of myelopathy scores with cervical sagittal balance and normalized spinal cord volume: analysis of 56 preoperative cases from the AOSpine North America Myelopathy study. Spine (Phila Pa 1976) 2013;38(22 Suppl 1):S161-70. Crossref
9. Shamji MF, Mohanty C, Massicotte EM, Fehlings MG. The Association of Cervical Spine Alignment with Neurological Recovery in a Prospective Cohort of Surgical Myelopathy Patients: Analysis of a Series of 124 Cases. World Neurosurg 2016;86:112-9. Crossref

10. Iwasaki M, Okuda S, Miyauchi A, Sakaura H, Mukai Y, Yonenobu K, Yoshikawa $\mathrm{H}$. Surgical strategy for cervical myelopathy due to ossification of the posterior longitudinal ligament: Part 2: Advantages of anterior decompression and fusion over laminoplasty. Spine (Phila Pa 1976) 2007;32(6):654-60. Crossref

11. Arvin B, Kalsi-Ryan S, Mercier D, Furlan JC, Massicotte EM, Fehlings MG. Preoperative magnetic resonance imaging is associated with baseline neurological status and can predict recovery in patients with cervical spondylotic myelopathy. Spine (Phila Pa 1976) 2013;38(14):1170-6. Crossref

12. Karpova A, Arun R, Cadotte DW, Davis AM, Kulkarni AV, O'Higgins M, Fehlings MG. Assessment of spinal cord compression by magnetic resonance imaging -can it predict surgical outcomes in degenerative compressive myelopathy? A systematic review. Spine (Phila Pa 1976) 2013;38(16):140921. Crossref

13. Fraser JF, Härtl R. Anterior approaches to fusion of the cervical spine: a metaanalysis of fusion rates. J Neurosurg Spine 2007;6(4):298-303. Crossref

14. Liu T, Xu W, Cheng T, Yang HL. Anterior versus posterior surgery for multilevel cervical myelopathy, which one is better? A systematic review. Eur Spine J 2011;20(2):224-35. Crossref

15. Emery SE, Bohlman HH, Bolesta MJ, Jones PK. Anterior cervical decompression and arthrodesis for the treatment of cervical spondylotic myelopathy. Two to seventeen-year follow-up. J Bone Joint Surg Am 1998;80(7):941-51.

16. Hirai T, Okawa A, Arai $Y$, Takahashi M, Kawabata S, Kato T, Enomoto M, Tomizawa S, Sakai K, Torigoe I, Shinomiya K. Middle-term results of a prospective comparative study of anterior decompression with fusion and posterior decompression with laminoplasty for the treatment of cervical spondylotic myelopathy. Spine (Phila Pa 1976) 2011;36(23):1940-7. Crossref

17. Wada E, Suzuki S, Kanazawa A, Matsuoka T, Miyamoto $\mathrm{S}$, Yonenobu K. Subtotal corpectomy versus laminoplasty for multilevel cervical spondylotic myelopathy: a longterm follow-up study of over 10 years. Spine (Phila Pa 1976) 2001;26:1443-7.

18. Cunningham MR, Hershman S, Bendo J. Systematic review of cohort studies comparing surgical treatments for cervical spondylotic myelopathy. Spine (Phila Pa 1976) 2010;35(5):537-43. Crossref

19. Hughes SS, Pringle T, Phillips F, Emery S. Settling of fibula strut grafts following multilevel anterior cervical corpectomy: a radiographic evaluation. Spine (Phila Pa 1976) 2006;31(17):1911-5. Crossref

20. Fehlings MG, Barry S, Kopjar B, Yoon ST, Arnold P, Massicotte EM, Vaccaro A, Brodke DS, Shaffrey C, Smith JS, Woodard E, Banco RJ, Chapman J, Janssen M, Bono C, Sasso R, Dekutoski $\mathrm{M}$, Gokaslan Z. Anterior versus posterior surgical approaches to treat cervical spondylotic myelopathy: outcomes of the prospective multicenter AOSpine North America CSM Study in 264 patients. Spine (Phila Pa 1976) 2013;38(26):224752. Crossref

21. Borden AG, Rechtman AM, Gershon-Cohen J. The normal cervical lordosis. Radiology 1960;74:806-9. doi: $10.1148 / 74.5 .806$ 
22. Benzel EC. Biomechanics of spinal stabilization. Rolling Meadows: American Association of Neurological Surgeons; 2001. p.526.

23. Lin Q, Zhou X, Wang X, Cao P, Tsai N, Yuan W. A comparison of anterior cervical discectomy and corpectomy in patients with multilevel cervical spondylotic myelopathy. Eur Spine J 2012;21(3):474-81. Crossref

24. Hilibrand AS, Carlson GD, Palumbo MA, Jones PK, Bohlman $\mathrm{HH}$. Radiculopathy and myelopathy at segments adjacent to the site of a previous anterior cervical arthrodesis. J Bone Joint Surg Am 1999;81(4):519-28.

25. Nunley PD, Jawahar A, Kerr EJ 3rd, Gordon CJ, Cavanaugh DA, Birdsong EM, Stocks M, Danielson G. Factors affecting the incidence of symptomatic adjacent-level disease in cervical spine after total disc arthroplasty: 2- to 4-year followup of 3 prospective randomized trials. Spine (Phila Pa 1976) 2012;37(6):445-51. Crossref

26. HightowerJM, Dhall SS, Haid RWJr, Rodts GEJr, Mummaneni PV. Treatment of cervical stenotic myelopathy: a cost and outcomes comparison of laminoplasty versus laminectomy and lateral mass fusion. J Neurosurg Spine 2011;14(5):61925. Crossref

27. Bohlman $\mathrm{HH}$. Cervical spondylosis with moderate to severe myelopathy: a report of 17 cases treated by Robinson anterior cervical discectomy and fusion. Spine 1977;2:151-62.

28. Kadoya S, Nakamura T, Kwak R. A microsurgical anterior osteophytectomy for cervical spondylotic myelopathy. Spine (Phila Pa 1976) 1984;9(5):437-43.

29. Zhang Z, Yin H, Yang K, Zhang T, Dong F, Dang G, Lou SQ, Cai $Q$. Anterior intervertebral disc excision and bone grafting in cervical spondylotic myelopathy. Spine (Phila Pa 1976) 1983;8(1):16-9.

30. Wang JC, McDonough PW, Endow KK, Delamarter RB. Increased fusion rates with cervical plating for two level anterior cervical discectomy and fusion. Spine (Phila $\mathrm{Pa}$ 1976) 2000;25(1):41-5.

31. Stachniak JB, Diebner JD, Brunk ES, Speed SM. Analysis of prevertebral soft-tissue swelling and dysphagia in multilevel anterior cervical discectomy and fusion with recombinant human bone morphogenetic protein-2 in patients at risk for pseudarthrosis: clinical article. J Neurosurg Spine 2011;14(2):244-9. Crossref

32. Liu $Y$, Hou $Y$, Yang $L$, Chen $H$, Wang $X$, Wu X, Gao R, Wang $C$, Yuan W. Comparison of 3 reconstructive techniques in the surgical management of multilevel cervical spondylotic myelopathy. Spine (Phila Pa 1976) 2012;37(23):E1450-8. Crossref

33. Shamji MF, Massicotte EM, Traynelis VC, Norvell DC, Hermsmeyer JT, Fehlings MG. Comparison of anterior surgical options for the treatment of multilevel cervical spondylotic myelopathy: a systematic review. Spine (Phila Pa 1976) 2013;38(22 Suppl 1):S195-209. Crossref

34. Nirala AP, Husain M, Vatsal DK. A retrospective study of multiple interbody grafting and long segment strut grafting following multilevel anterior cervical decompression. $\mathrm{Br} \mathrm{j}$ Neurosurg 2004;18(3):227-32.

35. Guo Q, Bi X, Ni B, Lu X, Chen J, Yang J, Yu Y. Outcomes of three anterior decompression and fusion techniques in the treatment of three-level cervical spondylosis. Eur Spine J 2011;20(9):1539-44. Crossref

36. Wei-bing X, Wun-Jer S, Gang L, Yue Z, Ming-xi J, Lian-shun J. Reconstructive techniques study after anterior decompression of multilevel cervical spondylotic myelopathy. J Spinal Disord Tech 2009;22(7):511-15. Crossref
37. Shen HX, Buchowski JM, Yeom JS, Liu G, Lin N, Riew KD. Pseudarthrosis in multilevel anterior cervical fusion with rhBMP-2 and allograft: analysis of one hundred twenty seven cases with minimum two-year follow-up. Spine (Phila $\mathrm{Pa}$ 1976) 2010;35(7):747-53. Crossref

38. Epstein NE. Anterior cervical discectomy and fusion without plate instrumentation in 178 patients. J Spinal Disord 2000;13(1):1-8.

39. Truumees E, Herkowitz HN. Cervical spondylotic myelopathy and radiculopathy. Instr Course Lect 2000;49:339-60.

40. Buchowski JM, Anderson PA, Sekhon L, Riew KD. Cervical disc arthroplasty compared with arthrodesis for the treatment of myelopathy. Surgical technique. J Bone Joint Surg Am 2009;91 Suppl 2:223-32. Crossref

41. Bruneau M, Cornelius JF, George B. Multilevel oblique corpectomies: surgical indications and technique. Neurosurgery 2007;61(3 Suppl):106-12. Crossref

42. Ozer AF, Oktenoğlu BT, Sarioğlu AC. A new surgical technique: open-window corpectomy in the treatment of ossification of the posterior longitudinal ligament and advanced cervical spondylosis: technical note. Neurosurgery 1999;45(6):1481-5.

43. Zhu B, Yu Y, Liu X, Liu Z, Dang G. Anterior approach versus posterior approach for the treatment of multilevel cervical spondylotic myelopathy: a systemic review and meta-analysis. Eur Spine J 2013;22(7):1583-93. Crossref

44. Hashimoto M, Mochizuki M, Aiba A, Okawa A, Hayashi K, Sakuma T, Takahashi H, Koda M, Takahashi K, Yamazaki M. C5 palsy following anterior decompression and spinal fusion for cervical degenerative diseases. Eur Spine J 2010;19(10):1702-10. Crossref

45. Ohashi M, Yamazaki A, Watanabe K, Katsumi K, Shoji H. Two-year clinical and radiological outcomes of open-door cervical laminoplasty with prophylactic bilateral C4-C5 foraminotomy in a prospective study. Spine (Phila Pa 1976) 2014;39(9):721-7. Crossref

46. Fehlings MG, Smith JS, Kopjar B, Arnold PM, Yoon ST, Vaccaro AR, Brodke DS, Janssen ME, Chapman JR, Sasso RC, Woodard EJ, Banco RJ, Massicotte EM, Dekutoski MB, Gokaslan ZL, Bono CM, Shaffrey Cl. Perioperative and delayed complications associated with the surgical treatment of cervical spondylotic myelopathy based on 302 patients from the AOSpine North America Cervical Spondylotic Myelopathy Study. J Neurosurg Spine 2012;16(5):425-32. Crossref

47. Schaffer JW, Field GA, Goldberg VM, Davy DT. Fate of vascularized and nonvascularized autografts. Clin Orthop Relat Res 1985;(197):32-43.

48. Samartzis D, Shen FH, Matthews DK, Yoon ST, Goldberg EJ, An HS. Comparison of allograft to autograft in multilevel anterior cervical discectomy and fusion with rigid plate fixation. Spine J 2003;3(6):451-9.

49. Bolesta MJ, Rechtine GR 2nd, Chrin AM. Three- and fourlevel cervical discectomy and fusion with plate fixation: a prospective study. Spine (Phila Pa 1976) 2000;25(16):2040-4.

50. Ba Z, Zhao W, Wu D, Shen B, Yu B, Wang Z. Box cages packed with local decompression bone were efficient in anterior cervical discectomy and fusion: five- to 10-year follow-up. Spine (Phila Pa 1976) 2012;37(20):E1260-3. Crossref

51. Pechlivanis I, Thuring T, Brenke C, Seiz M, Thome C, Barth M, Harders A, Schmieder K. Non-fusion rates in anterior cervical discectomy and implantation of empty polyetheretherketone cages. Spine (Phila Pa 1976) 2011;36(1):15-20. Crossref 
52. Niu CC, Liao JC, Chen WJ, Chen LH. Outcomes of interbody fusion cages used in 1 and 2-levels anterior cervical discectomy and fusion: titanium cages versus polyetheretherketone (PEEK) cages. J Spinal Disord Tech 2010;23(5):310-6. Crossref

53. Uribe JS, Sangala JR, Duckworth EA, Vale FL. Comparison between anterior cervical discectomy fusion and cervical corpectomy fusion using titanium cages for reconstruction: analysis of outcome and long-term follow-up. Eur Spine J 2009;18(5):654-62. Crossref

54. Sasso RC, Ruggerio RA Jr, Reilly TM, Hall PV. Early reconstruction failures after multilevel cervical corpectomy. Spine (Phila Pa 1976) 2003;28(2):140-2. Crossref

55. Jeyamohan SB, Kenning TJ, Petronis KA, Feustel PJ, Drazin D, DiRisio DJ. Effect of steroid use inanterior cervical discectomy and fusion: a randomized controlled trial. J Neurosurg Spine 2015;23(2):137-43. Crossref

56. Emery SE, Smith MD, Bohlman HH. Upper airway obstruction after multilevel cervical corpectomy for myelopathy. J Bone Joint Surg Am 1991;73(4):544-51.

57. Riew KD, Won DS, Calvert G, et al. Parameters for maintaining intubation postoperatively following anterior cervical procedures. Seattle, WA: Proceedings of the 16th Annual Meeting North American Spine Society; 2001.
58. Katsuura A, Hukuda S, Saruhashi Y, Mori K. Kyphotic malalignment after anterior cervical fusion is one of the factors promoting the degenerative process in adjacent intervertebral levels. Eur Spine J 2001;10(4):320-4.

59. Yonenobu K, Fuji T, Ono K, Okada K, Yamamoto T, Harada N. Choice of surgical treatment for multisegmental cervical spondylotic myelopathy. Spine (Phila Pa 1976) 1985;10(8):710-6.

60. Yonenobu $\mathrm{H}$, Hosono $\mathrm{N}$, Iwasaki M, Asano M, Ono K. Laminoplasty versus subtotal corpectomy: a comparative study of results in multisegmental cervical spondylotic myelopathy. Spine (Phila Pa 1976) 1992;17(11):1281-4.

61. Edwards C 2nd, Heller JG, Morikami H. Corpectomy versus laminoplasty for multi-level cervical myelopathy: an independent matched cohort study. Spine (Phila Pa 1976) 2002;27(11):1168-75.

62. Oh MC, Zhang HY, Park JY, Kim KS. Two-level anterior cervical discectomy versus one-level corpectomy in cervical spondylotic myelopathy. Spine (Phila Pa 1976) 2009;34(7):692-6. Crossref 